\title{
Resilience ability and SME survival rate in the middle of business environmental fluctuation
}

\author{
Ahmad Syaiful Affa ${ }^{1}$, Muh. Ghafur Wibowo ${ }^{2}$, Izra Berakon ${ }^{3}$ \\ ${ }^{1}$ Faculty of Economics, Universitas Pekalongan, Indonesia \\ ${ }^{2,3}$ Faculty of Economics and Islamic Business, UIN Sunan Kalijaga, Indonesia
}

\begin{abstract}
Purpose - This study examines the effect of organizational resilience variables on the firm's survival rate and the moderating role of environmental turbulence variables in the relations of organizational resilience and firm survival.

Method - This study uses simple regression to test research hypotheses. Primary data in the form of questionnaires are obtained from Small and Medium Enterprises (SMEs) in Java.

Result - The analysis shows that organizational resilience variables can improve the firm's survival. However, this study did not find the moderating role of environmental turbulence in influencing the relationship between organizational resilience variables and firm survival.
\end{abstract}

Implication - This study can help scholars and practitioners to understand more of the mechanism of organizational resilience and its impact on survival on smaller firms.

Originality - This study offer the empirical study of firm survival on smallmedium enterprise setting in Indonesia.

Keywords: resilience, SME, firm survival, environmental fluctuation 


\section{Introduction}

Challenges and disruptions that can threaten business continuity vary from levels, frequencies, and sources that come from internal and external companies. Challenges and disruptions can

JIEMB | 2 also come at any time, which can be in the form of natural disasters, terrorist attacks, economic crises, changes in the business environment, technological evolution, equipment damage and human error (Bhamra et al., 2011). Tactics and strategies that can increase the lifespan of an organization have become an interesting research topic in the field of strategic management during recent years, such as research conducted by Hamel and Valikangas (2003); Carmelli and Markman (2011); Rahman et al. (2016) and Kim and Lee (2016).

The concept of strategic management is very helpful in business, but the survival rate of companies, especially Small and Medium Enterprises (SMEs) is still very low. Out of 10 small businesses, only 7 companies are able to survive in their first year of operation, and only 2 companies are still able to continue operations in the company's fifth year of existence (Carmelli and Markman, 2011). Carmelli and Markman added that 50 to 70 percent of companies went out of business in the first year of operation and 80 percent more stopped operating in the first 10 years of existence, and many companies were able to survive but were unable to thrive.

In Indonesia, as in several other developing countries, SMEs are the biggest pillars of the country's economy. It is recorded that in developed countries such as the United Kingdom (UK), the total number of SMEs is more than $99 \%$ in that country, with the criteria of SMEs that employ fewer than 250 people and a total annual asset turnover of fewer than 50 million Euros. In Indonesia, the number of SMEs compared to large businesses according to data from the Central Statistics Agency (BPS) has reached 99.9\% and the number of workers absorbed by SMEs has increased this year, from $96.99 \%$ to $97.22 \%$ of the total national workforce. SMEs in Indonesia also contributed GDP to the State amounting to 980 trillion rupiahs as of August 2017, an increase of $57.84 \%$ to $60.34 \%$ with the number reaching 60 million SME units in 2017 (BPS, 2017).

Although the level of organizational failure is a concern, there is no specific theory that is interrelated between what tactics and strategies can increase the level of organizational life (Carmelli and Markman, 2011). In the last few decades, many scientists in the 
social field have adopted theories from other fields of science, especially in the level of corporate life, researchers have adopted from the field of ecology. One of the theories developed in the study of organizational life at this time is the theory of organizational resilience which is adopted from the concept of ecological resilience, this concept was introduced by Holling (1973) which links organizational resilience to ecology and environmental topics.

Although organizational resilience has been widely researched in the literature, there are still few that place organizational resilience as the main focus in empirical research. A review conducted by Annarelli and Nonino (2016) shows that less than $40 \%$ of articles on organizational resilience in management and business are empirical studies, the rest are still conceptual studies. From the empirical studies studied, $64 \%$ were case studies, $28 \%$ were surveyed and the remaining $8 \%$ were action research. The lack of empirical research means that organizational resilience is still not generally accepted and further research is needed to get a clearer picture of the impact and results of the company's organizational resilience.

In the context of improving company performance, the concept of organizational resilience has not received special attention as the main variable in research (Akgün \& Keskin, 2014). Although in conceptual studies, organizational resilience is believed to have a positive influence on the survival of company. There is still little empirical evidence that can explain this research. Organizational resilience is often viewed only in terms of its passive concept, where organizational resilience is only considered as the ability of a system to return to its original position after experiencing a shock (Bhamra et al., 2011). In fact, from a more dynamic side, organizational resilience can control the output produced by the organization in controlling dependence on the company's external environment (Rose, 2004).

Therefore, researchers feel the need to see to what extent the concept of organizational resilience can affect the survival rate of a company in this very volatile environment. The research was conducted in Indonesia, especially in Java, where the number of SMEs in this area is the largest compared to the total of all SMEs in Indonesia, which is around $73 \%$ so that it can represent the state of SMEs in Indonesia (BPS Data, 2015). This study examines the effect of SME organizational resilience capabilities on the survival rate of Journal of Islamic Economics, Management, and Business-Vol 2. No.1 (2020 
the company and whether environmental fluctuations moderate the effect of SME organizational resilience capabilities on the company's survival rate.

\section{JIEMB | 4 Literature review}

Holling (1973) defines the resilience of an ecosystem, which is a measure of its ability to absorb change and be able to exist. When compared with other similar concepts, namely stability, there is a difference that (organizational) resilience places more emphasis on the level of ability to absorb changes and shocks so that the system (organization) can still survive. The output generated by resilience is survival and the possibility to survive, while stability measures how quickly a system or organization can return to its original position after experiencing a shock. The less the level of fluctuation and the faster a system can return to its original position after experiencing a shock, the system is said to be stable.

Given the ecological theory that is adapted and contributes to the development of strategic management, the concept of organizational resilience fits well with the environmental exchange theory developed by Emerson (1962) and Blau (1964). Environmental exchange theory talks about how an organization responds to input from its environment, both external and internal. Environmental exchange theory also talks about how organizations (especially decision-makers) have a role in determining organizational output that can provide results from the value that has been obtained from the external environment (Jemison, 1981).

Meanwhile, another ecological theory (population ecology) which was initiated by Darwin in 1859, explained that organizations are very dependent on the external environment of the company and only organizations that can adapt can survive. In the theory of population ecology, organizations are seen as having almost no power to control their external environment, so that the internal capabilities of the organization are ignored.

From the two conflicting theories above, the concept of organizational resilience is seen as the internal ability of an organization which has the power to provide output within the organization to control organizational dependence from its external environment, so that organizations can play a role in building their survival, not only depending on and adapting to their external 
environment. The definition of the concept of organizational resilience differs in views from various fields of science as in Table 1 , but there is a similarity in concept, namely where organizational resilience refers to the ability of a company or organization to survive after experiencing shocks and minimize the potential for future uncertainty obtained from environmental fluctuation in a continuous manner (Bhamra et al., 2011).

Annarelli and Nonino (2016) explain that company resilience is the ability to deal with unexpected events with the help of strategic awareness and company operational management. At this time, the level of climate change, economic volatility, and social systems has increased beyond the capabilities of the organization (Gibson \& Tarrant, 2010) and the concept of organizational resilience is seen as one of the keys to an organization's ability to be able to maintain its performance sustainably in a volatile environment (Ates \& Bititci, 2011).

Like special abilities that are attached to environmental fluctuations, organizational resilience is considered more reliable in conditions of high environmental volatility, such as research conducted by Akgün and Keskin (2014) which explains how

Table 1. Definition of Resilience by Field of Science (Bhamra et al., 2011)

\begin{tabular}{|c|c|c|c|}
\hline No & Authors & Context & Definition of resilience \\
\hline 1 & Holling (1973) & $\begin{array}{l}\text { Ecological } \\
\text { systems }\end{array}$ & $\begin{array}{l}\text { The measure of the persistence of systems } \\
\text { and of the ability to absorb change and } \\
\text { disturbance and still maintain the same } \\
\text { relationships between state variables }\end{array}$ \\
\hline 2 & $\begin{array}{l}\text { Carpenter et al } \\
(2001)\end{array}$ & Socio-ecological & $\begin{array}{l}\text { The magnitude of disturbance that a } \\
\text { system can tolerate before its transitioning } \\
\text { into a different state that is controlled by a } \\
\text { different set of processes }\end{array}$ \\
\hline 3 & $\begin{array}{l}\text { Luthans et al } \\
(2006)\end{array}$ & Psychology & $\begin{array}{l}\text { The developable capacity to rebound from } \\
\text { adversity }\end{array}$ \\
\hline 4 & $\begin{array}{l}\text { Bruneau et al } \\
(2003)\end{array}$ & $\begin{array}{l}\text { Disaster } \\
\text { management }\end{array}$ & $\begin{array}{l}\text { The ability of social units to mitigate } \\
\text { hazards, contains the effects of disasters } \\
\text { when they occur, and carry out recovery } \\
\text { activities that minimize social disruption } \\
\text { and mitigate the effects of future } \\
\text { earthquakes }\end{array}$ \\
\hline 5 & Coutu (2002) & Individual & $\begin{array}{l}\text { Resilient individuals' posses three common } \\
\text { characteristics: acceptance of reality, a } \\
\text { strong belief that life is meaningful, and the } \\
\text { ability to improvise }\end{array}$ \\
\hline 6 & $\begin{array}{l}\text { Hamel and } \\
\text { Valikangas }\end{array}$ & Organizational & $\begin{array}{l}\text { Resilience referring to the capacity to } \\
\text { continuous reconstruction }\end{array}$ \\
\hline
\end{tabular}
(2003) 
environmental fluctuation is also a moderating factor for the relationship between organizational resilience and product innovation, where the higher the environmental fluctuation in the JIEMB | 6 organization, the higher the impact of the company's resilience to innovate. This is in line with the opinion of Hamel and Valikangas (2003) who make organizational resilience a special ability in dealing with a very volatile environment.

Research suggests that the concept of organizational resilience is considered capable of responding to the need for coping and healing from the effects of environmental shocks that occur. In particular, organizational resilience plays a role as well as prepares resources in dealing with the uncertainty problems faced so that companies can stay alive for a longer period (Hamel \& Valikangas, 2003; Rose, 2004; Carmelli \& Markman, 2011, Bhamra et al., 2011).

Elements of organizational resilience are considered to have in common with the attributes of an organization such as flexibility (the ability to change under certain circumstances), adaptability (the ability to adapt to the environment), and agility (the ability to build and apply dynamic change quickly) (Lengnick-Hall et al., 2011), but there are important differences between the three as described in Table 2. It is explained that the concept of organizational resilience is the main variable that can stand alone, in contrast to the three other concepts that still require other variables to work, so that the output generated from resilience ability organization is different from other concepts (Lengnick-Hall et al., 2011).

Table 2. Differences in the concept of organizational resilience (Hair et al., 2011)

\begin{tabular}{lll}
\hline No & Organizational Resilience & Related Variables \\
\hline 1 & $\begin{array}{l}\text { The need for organizational resilience } \\
\text { is triggered by an unwanted event. }\end{array}$ & $\begin{array}{l}\text { Flexibility and agility are part of the ongoing } \\
\text { strategic plan to increase the company's } \\
\text { movement. } \\
2\end{array}$ \\
$\begin{array}{l}\text { Organizational resilience combines } \\
\text { renewal, transformation and dynamic } \\
\text { creativity that originates from inside } \\
\text { and outside the company. }\end{array}$ & $\begin{array}{l}\text { Adaptability places more emphasis on the } \\
\text { suitability of the environment that comes } \\
\text { from outside into the company. }\end{array}$ \\
& $\begin{array}{l}\text { Organizational resilience is the main } \\
\text { variable that can stand alone. }\end{array}$ & $\begin{array}{l}\text { Although flexibility, agility and adaptability } \\
\text { contribute to creating organizational } \\
\text { resilience capabilities, the three of them are } \\
\text { unable to work alone in achieving it. }\end{array}$ \\
\hline
\end{tabular}




\section{Organizational resilience and corporate survival}

In an increasingly interconnected world (social, technological and environmental) no organization can maintain a competitive position and survive disruption as a stand-alone entity (Bhamra et al., 2011). One of the keys to survival is obtaining resources and maintaining them, but no single organization can meet its own needs (Pfeffer \& Salancik, 2003). In order to be successful in dealing with changing volatile environments, organizations need to improve how they deal with unexpected disruptions (Fiksel, 2015). Organizations should not only focus on the vulnerability of the system to failure, but also the ability to manage and minimize the impact of these failures (Dalziell \& McManus, 2004).

One of the abilities that can meet the needs of the challenges faced by the organization is the ability of organizational resilience (Hamel \& Valikangas, 2003; Rose, 2004; Carmelli \& Markman, 2011, Bhamra et al., 2011). Organizational resilience refers to an organization's ability to deal with disruptions and unexpected events due to strategic awareness and operational management related to internal and external shocks (Annarelli and Nonino, 2016). In the crisis period, organizational resilience is even more needed, especially in industrial processes, because in this condition when one process fails it will have an impact on other processes (Aleksic et al., 2013). Prolonged failure of the production process will result in failure of company operations and have an impact on the sustainability of the organization.

Fiksel (2015) adds that organizational resilience means improving the adaptability of supply chains globally, collaborating with stakeholders and utilizing information technology to ensure sustainability, even in the face of disaster disruption. Organizational resilience is more than just mitigating risk, organizational resilience capability enables a business to gain a competitive advantage by learning how to deal with distraction more effectively than its competitors and possibly shift to a new equilibrium. Small-medium scale companies are very lacking in terms of planning and risk mitigation (Bhamra et al., 2011). To increase sustainability and resilience, especially SMEs, it requires the ability to embrace various organizational dimensions and pay attention to long-term organizational planning (Ates \& Bititci, 2011).

From the initial characteristics of organizational resilience which are very close to the level of life of the company, the ability of Journal of Islamic Economics, Management, and Business-Vol 2. No.1 (2020 
company organizational resilience can have a direct effect on the level of life of the company. This is supported by research conducted by Watanabe et al. (2004) who found that organizational resilience is a source of corporate strategy to be able to live in a very high environmental competition. Therefore, from the research data above, the researcher proposes the first hypothesis, namely:

Hypothesis 1: Organizational resilience has a positive effect on the survival rate of the company

\section{Environmental fluctuation, organizational resilience and corporate survival rate}

In a study conducted by Akgün and Keskin (2014), the environmental fluctuation is also a moderating factor for the relationship between resilience and product innovation, where the higher the environmental fluctuation in the organization, the higher the company's resilience will influence innovation. This is in line with the opinion of Hamel and Valikangas (2003) who make organizational resilience a special ability in dealing with a very volatile environment.

The moderating variable of environmental volatility can influence the strength of the causal relationship between organizational resilience and firm survival rates, which may imply a weakening of the relationship, strengthen or even reverse the effect of a firm's organizational resilience. In a study conducted by Chi and Sun (2013), environmental fluctuation affects the relationship between a company's organizational structure and the level of a company's export orientation behavior. In a more volatile environment, formal structures and centralized authority in companies prevent them from adapting to rapid changes in customers, competitors, technology, and regulations. Environmental fluctuation in this study is a rapid change that can be seen in customer preferences,

The negative impact of environmental fluctuation on organizational performance comes from unexpected environmental fluctuation (Wang \& Fang, 2012). The ability of a company's organizational resilience is very closely related to high environmental fluctuations so that it can have a positive effect because the company's organizational resilience is not only anticipating unexpected risks but is also a self-preparation process before unexpected events come (Rose, 2004; Hamel \& Valikangas, 2003, Bhamra et al., 2013; Annarelli \& Nonino, 2016). The higher the 
fluctuation of environmental symptoms, the higher the effect of the company's organizational resilience on the company's survival rate.

Another study conducted by Pratono and Mahmood (2014) explains that the moderating effect of environmental fluctuation can change the direction of the relationship between entrepreneurial management and company performance. During low environmental volatility, entrepreneurial management has a positive impact on company performance, but the direction changes when the level of environmental volatility is high. This is very vulnerable to occur in small and medium-scale organizations because organizations at this level do not have the strength to anticipate risks originating from the external environment (Gunasekaran et al., 2011).

SMEs that are very vulnerable to disruption from the external environment can be driven by the ability of the company's organizational resilience when the company is in an environment with high levels of competition and volatility (Gunasekaran et al., 2011). External disruptions experienced by companies, especially SMEs, are varied, ranging from economic crises that have caused a weak global economy to natural disasters that can paralyze the supply chain from or to related organizations (Bhamra et al., 2011). The ability of organizational resilience also expands knowledge, skills, and technical abilities, which can provide options for improvising and seeking various alternatives related to products in very volatile environmental conditions (Akgün \& Keskin, 2014).

Indicators developed to measure environmental fluctuations in market orientation studies can come from market volatility and technology volatility (Jaworski \& Kohli, 1993; Akgün \& Keskin, 2014). Market volatility shows the extent to which the level of needs and tastes of the company's customers change. Technological volatility refers to the speed at which the technology involved in operational operations changes. From the above study, the researcher formulates the effect of moderating environmental fluctuation on the second hypothesis in this study, namely: Hypothesis 2 Environmental fluctuation moderates the relationship between organizational resilience and company survival. In conditions of high environmental fluctuation, the positive influence of the company's organizational resilience on the company's survival rate is greater than in conditions of low environmental fluctuation. 
Hypothesis 2: Environmental fluctuation moderates the effects of organizational resilience on firm survival. In conditions of high environmental volatility, the positive influence of the company's organizational resilience on the company's survival rate is greater than in conditions of low environmental volatility.

\section{Methodology}

The data used in this research are primary data, were taken directly by researchers from respondents (Cooper and Schindler, 2011). The collection of the data in this study was done through a survey method by asking questions directly through print, digital or other media. The unit of analysis of this research is the organization, in the context of this study, it is a small and medium scale company. The data that have been collected are then analyzed with the help of data processing software and the results are then interpreted.

The population is the overall object of research that will be studied (Cooper and Schindler, 2011), in the context of this study, are all small and medium enterprises in Indonesia. The sample is a portion of the population selected to be able to represent the population by certain selection methods. The sample selection in this study using a purposive sampling technique with a nonprobability sampling method. The criteria for the sample in this study are:

1. SMEs that can withstand the fluctuation of environmental changes and operate for a minimum of three years (minimum age for SMEs is 3 years), and are located on the island of Java ( $74 \%$ of all SMEs in Indonesia).

2. Companies that fall into the criteria for Small and Medium Enterprises (UKM) in terms of the number of employees and turnover. In terms of the number of employees, according to the criteria from Kadin and $\mathrm{BI}$, a company can fall into the SME category if the employees in the company are fewer than 300 people (Subanar, 2001).

\section{Operational definition and measurement}

This study adapts the research instruments that have been used previously. There are three latent variables and two control variables that will be collected from each respondent. The variables in this study are described as follows: 


\section{Organizational Resilience.}

Measurement of organizational resilience variables is taken from Akgün and Keskin (2014) which was adapted from previous conceptual research by Lengnick-Hall et al. (2011). Organizational resilience variable originates from the concept of individual resilience that has been developed previously. Lengnick-Hall et al. (2011) argue that understanding individual resilience is a very appropriate first step to seeing organizational resilience, because behavior and interactions between individuals in the organization are the contributors to the emergence of an organization's collective ability for organizational resilience.

Lengnick-Hall et al. (2011) argue that capacity for resilience is a unique combination of cognitive abilities, behavioral and contextual abilities as well as routines at the organizational level. Researchers also found capacity for resilience in the organization level is obtained from a combination of knowledge (knowledge), skill (skills), ability (abilities) and other attributes (other's attribute) (KSAO's) at the level of individuals who systematically integrated through empowerment system resources human power in the organization.

Furthermore, Lengnick-Hall et al. (2011) summarized the points in the organization that can represent organizational resilience in three dimensions, namely cognitive, behavioral and contextual dimensions. By Akgün and Keskin (2014) the points described by Lengnick-Hall et al. (2011) were translated into questions and tested. Initially, 9 dimensions of the construct of organizational resilience were formed, but after going through empirical testing withmethods Exploratory Factor Analysis (EFA) and Confirmatory Factor Analysis structured (CFA), the final results were six categories representing organizational resilience, namely competence orientation (8 items), deep social capital (4 items), original / unscripted agility ( 3 items), practical habits (2 items), broad resource network (2 items) and behavioral preparadness (2 items).

These six categories, each of which have several items, are later used as a measuring tool for organizational resilience. One example of a question in measuring organizational resilience that represents the category of competence orientation is "We have an open mindset and positive perceptions of new experiences in the 
organization". Overall statements were assessed on a 5-pointscale Likert, ranging from "Strongly Disagree (1)" to "Strongly Agree (5)".

\section{Corporate survival rate}

The survival of the company is the dependent variable that JIEMB | 12 measures the performance of the company as seen from how the company survives in various environmental turmoil (Naidoo, 2010). Measurement for firm survival variables uses the perceptual construct developed by Naidoo (2010) adapted from Sinha and Noble (2008). Subjective measures (perceptual construct) were chosen compared to objective measures (financial data) for several reasons. First, the absolute value generated by objective measurement can be influenced by factors related to industry (Covin \& Slevin, 1989; Miller \& Toulouse, 1986).

Second, because the object of research is at the SME level, the possibility of obtaining objective measurements is very difficult, so that subjective measurement with perceptual constructs is more suitable to be applied in this study (Newbert, 2008). One example of a question in measuring the company's survival variable is "Our organization is still able to withstand the crisis and environmental turmoil". The company's survival variable is assessed on a 5pointscale, Likert which ranges from "Strongly Disagree (1)" to "Strongly Agree (5)".

\section{Environmental turmoil Environmental}

Environmental turmoil measures the extent to which the level of environmental uncertainty or fluctuation that occurs in the organization's external environment. In this case, the measurement is based on the perception of organizational leaders about how environmental conditions have so far been experienced (Akgün \& Keskin, 2014). Measurement of environmental fluctuation variables used the instrument used by Akgün and Keskin (2014) which was adapted from Jaworski and Kohli (1993).

Three question items are each given to represent the turmoil of technology and market volatility. Technological volatility is related to technological changes for new products and market volatility is related to changes in customer preferences. One example of a question in measuring environmental fluctuation variables that represent the dimensions of technological turmoil is "Technology in this industry is changing very rapidly". In this study, the measurement of environmental fluctuation will later be used to 
divide environmental conditions into two, namely organizations with low and high environmental turmoil conditions. This division is used to see the difference in the effect of organizational resilience during low or high environmental shocks (Naidoo \& Leonard, 2007). The overall variables of environmental volatility are assessed on a 5pointscale Likert , ranging from "Strongly Disagree (1)" to "Strongly Agree (5)".

\section{Control variable}

Although it is not the main focus of the study, control variables are needed because they are indicated to affect the main variables in the study. The control variables used in this study arefirm ageandfirm sizewhich are measured using a ratio scale. The age of the company is obtained from the number of years since the establishment of the company to date, while thefirm size isobtained from the number of employees in the company.

\section{Data analysis techniques}

Before testing the hypothesis, first testing the research instruments was conducted which include validity and reliability tests. The validity test is carried out to see to what extent the level of the test measures what is really being measured (Cooper \& Schindler, 2014). The validity test aims to measure the quality of the instrument used, namely the level of validity of the instrument shows how well a concept can be defined by a measuring instrument. This validity test is carried out in two ways, namely the face validity test and the construct validity test. A face validity test is required at the beginning of the study to increase confidence in scale making and in subsequent validity tests (Hardesty \& Bearden, 2004). The face validity test is carried out by asking for assessment, confirmation and direction from the supervisor, colleagues and other parties who are more competent.

This study utilized the test construct validity by using Confirmatory Factor Analysis (CFA). In the CFA method, the value of the factor loading construct is taken into consideration with a minimum limit of thevalue, factor loading namely 0.4 (Hair et al., 2010). In addition to factor loading, the value of cross loading is also considered, that is if there is a value cross loading, the discriminant validity of the study is not fulfilled and the instrument may not be used (Hair et al., 2010). 
After seeing the value of factor loading and cross loading, factor analysis is considered feasible according to Hair et al. (2010) if they meet the following requirements:

1. The results of the Kaiser-Meyer-Olkin (KMO) and Balett's Test show a value above 0.50 with a significance level of 0.05 .

2. Thecoefficient Anti Image Matrices as a Measure of Sampling Adequacy (MSA) is at least 0.50 .

\section{Reliability testing}

Reliability test is related to the accuracy and precision of a measurement procedure (Cooper \& Schindler, 2014). The reliability test is used to see to what extent the measurement results remain consistent if they are carried out twice or more on the same phenomenon and using the same measuring instrument (Hair et al., 2010). Reliability test is an important test but not a mandatory aspect of validity (Cooper \& Schindler, 2014). Reliability testing is done after the validity test. Reliability testing is done by calculating the Cronbach's alpha value for more than one measurement item. The cronbach's alpha requiredvalue must be greater than 0.60 (Hair et al., 2010).

\section{Hypothesis testing}

This study uses simple regression to test the research hypotheses. To test the first hypothesis, a simple regression was carried out between the variable organizational resilience and firm survival. Meanwhile, to test the second hypothesis, namely the moderating role of environmental fluctuation variables in the relationship between organizational resilience and company survival, simple regression was carried out using sub-group analysis technique.

The subgroup analysis technique aims to see the effect of independent variables on the dependent variable in groups with different moderation characters (high and low) (Kohli, 1989). This analysis technique is carried out by looking at the effect of the independent and dependent variables after dividing the moderating variables into two different groups (high and low) (Dawson \& Richter, 2006).

In this study, regression analysis was performed using SPSS software. The steps involved in testing the hypotheses using the regression method are as follows: 
1. To test hypothesis 1 , a simple regression test is carried out between the independent variables of organizational resilience against the dependent variable for firm survival with the following equation:

$$
Y=\alpha+\beta X
$$

With:

$$
\begin{aligned}
& \mathrm{Y}=\text { company survival variable (bound) } \\
& \mathrm{X}=\text { organizational resilience variable (free) }
\end{aligned}
$$

2. Perform simple regression testing between organizational resilience variables and company survival in the moderation group which is divided into two, namely groups with low and high environmental volatility (Naidoo and Leonard, 2007). The equation used to test hypothesis 2 is as follows:

$$
\begin{aligned}
& Y=a+\beta \text { low } X . \\
& Y=\alpha+\beta \text { highX }
\end{aligned}
$$

Equation (2) is used to test the organizational resilience variable on the company's survival in groups with low environmental fluctuation, while equation (3) is used to test the organizational resilience variable on the company's survival in groups with high environmental volatility.

\section{Perform Chow-test calculations}

The Chow test is used to test the coefficient similarity, to find out whether the results of observations divided into two groups have the same coefficient or not (Ghazali, 2015).

The formula used is as follows:

With:

$$
\begin{aligned}
& \text { S1 = Residual value sum of square testing equation } 1 \\
& \text { S2 }=\text { Residual value sum of square testing equation } 2 \\
& \text { S3 = Residual value sum of square testing equation } 3 \\
& k \quad=\text { Estimated number of parameters / groups } \\
& \text { n1 = Number of samples in the group at high moderation } \\
& \text { n2 }=\text { Number of samples in the low moderator group. }
\end{aligned}
$$

\section{Comparing $F$ count and $F$ table.}

If $F$ count is greater than $F$ table, it can be concluded that the variable environmental fluctuation significantly moderates the effect of organizational resilience on company survival. The formula for $F$ table is df1 = k; df2 = n1 + n2-2k 
Comparing the regression significance values and comparing $\beta$ (beta) groups high and low groups. In this study, if $\beta$ high $<\beta l o w$, the positive effect of organizational resilience on the company's survival will be higher in the high environmental volatility group.

JIEMB | 16

\section{Results and discussion}

\section{The results of the validity test}

This study used the face validity test and the construct validity test, the face validity test was used so that the respondent could understand what was meant by the question in the study. The face validity test is done by asking for opinions from people who are more proficient in this case lecturers and academic colleagues who are more experienced in conducting research. Meanwhile, to test the construct validity, researchers tested the discriminant validity and convergent validity by conducting Component Factor Analysis (CFA).

From the test results using SPSS 23 software, the KaiserMeyer-Olkin Measure of Sampling Adequacy (KMO-MSA) value is 0.520 and the Bartlett's Test of Sphericity is significant at 0.000 (see table 3 ). This value indicates that this study has met the sample adequacy requirements of 0.5 and thevalue Bartlett's Testis less than 0.05 (Hair et al., 2010).

In addition to meeting the sample adequacy requirements, the validity of the discrimination was carried out by looking at the loading factor in the measurement construct. The loading factor value which is the standard measurement is 0.4 (Hair et al., 2010). From the data generated through testing the CFA analysis by dividing all indicators into a maximum of 3 components, there are problems, namely two indicators of the company's survival variable and nine indicators of organizational resilience variables that do not meet the requirements to be included in the next test, so the indicators must be removed. After adjustments were made to several indicators of the variable of company survival and

Table 3. Table of KMO values and the Barlett Test

\begin{tabular}{lll}
\hline \multicolumn{2}{c}{ Kaiser-Meyer-Olkin Measure of Sampling Adequacy } & 0,520 \\
\hline \multirow{3}{*}{ Bartlett's Test of Sphericity } & Approx. Chi-Square & 886,966 \\
& $\mathrm{df}$ & 465 \\
& Sig. & 0,000 \\
\hline
\end{tabular}


Table 4. Value Results Factor analysis

\begin{tabular}{|c|c|c|c|c|c|c|c|}
\hline \multirow[t]{2}{*}{ Variables } & \multicolumn{3}{|c|}{ Rescaled } & \multirow[t]{2}{*}{ Variables } & \multicolumn{3}{|c|}{ Rescaled } \\
\hline & 1 & 2 & 3 & & 1 & 2 & 3 \\
\hline FS1 & & & 0.603 & RES9 & & 0.603 & \\
\hline FS2 & & & 0.508 & RES10 & & 0.547 & \\
\hline RES1 & & 0.524 & & RES11 & & 0,483 & \\
\hline RES2 & & 0.599 & & RES12 & & 0.445 & \\
\hline RES3 & & 0.666 & & ENT1 & 0,462 & & \\
\hline RES4 & & 0.701 & & ENT2 & 0,559 & & \\
\hline RES5 & & 0.611 & & ENT3 & 0.611 & & \\
\hline RES6 & & 0.553 & & ENT4 & 0.570 & & \\
\hline RES7 & & 0.657 & & ENT5 & 0.607 & & \\
\hline RES8 & & 0.450 & & ENT6 & 0.650 & & \\
\hline
\end{tabular}

organizational resilience, the measurement of this study was declared valid and passed the validity test so that it was declared eligible for further testing. Variables and indicators that have passed the validity test can be seen in Table 4.

Variables that pass this validity test are obtained by rotating with the Varimax method seven times, with a an eigen value cumulative of $71.07 \%$ which means that all indicators are in the survival company variable. Rrganizational resilience and environmental turmoil represent as much as $71 \%$ of the total variation produced.

\section{Reliability test results}

Determination of reliability in this study used values of Cronbach's alpha. The Cronbach's alpha value is used to assess the consistency of each indicator in measuring certain variables (Hair et al., 2010). The value required to be able to meet the reliability test is that the value of Cronbach's alpha in the study must be greater than 0.60 (Hair et al., 2010).

From the measurement results, the obtained Cronbach's alpha value of each variable was obtained by eliminating several questions that did not pass the validity test. The company's survival variable has a Cronbach's alpha value of 0.640 with two questions, the organizational resilience variable has a Cronbach's alpha value of 0.806 with 13 questions and the environmental fluctuation variable has a Cronbach's alpha value of 0.769 with 6 questions.

Table 5. Value of Cronbach's Alpha

\begin{tabular}{lll}
\hline Variable & Cronbach's alpha & Item \\
\hline Survival of the company & 0.640 & 2 \\
Organizational resilience & 0.806 & 13 \\
Environmental turbulence & 0.769 & 6 \\
\hline
\end{tabular}




\section{Hypothesis testing}

In this study, two hypotheses were tested; direct effect hypothesis and the moderating effect hypothesis. The direct effect was tested using simple regression analysis, while the moderating effect analysis was tested by sub-group analysis by grouping the low and high environmental turmoil groups using an approach as previously done by Naidoo and Leonard (2007) and Visita (2016). The results of the analysis of the initial interaction between the main variables and control variables are shown in Table 6.

Table 6 shows the value of $R^{2}$ for the control variable test model of 0.009 . This value indicates that the control variables (Age and Company Size) can explain the variation in firm survival by only $0.9 \%$ and the remaining $99.1 \%$ is explained by other variables outside the model. While the influence of the test by entering the main variables in Table 6 shows the value of $R^{2}$ increased to 0.104 . This indicates that there is an additional explanation for variations in the survival of the company survival amounted to $9.5 \%\left(R^{2}=0.104\right)$, when the organizational resilience variable is included in the research model.

The explanation for the variation in the company's survival increased from $0.9 \%$ to $10.4 \%$. In Table 6 , it can also be seen that the significance value does not meet the $5 \%$ or $10 \%$ tolerance standard before or after the organizational resilience variable is entered into the model. In this case it can be concluded that the

Table 6. Results of the interaction analysis of main variables and control variables

\begin{tabular}{lccc}
\hline \multirow{2}{*}{ Variable } & Survival & & \\
\cline { 2 - 4 } & $\boldsymbol{B}$ & $\mathbf{t}$ & $\boldsymbol{\rho}$ \\
\hline \multicolumn{1}{c}{ Control variables } & & & \\
Age of the firm & 0.061 & 0.426 & 0.672 \\
Size of the firm & 0.058 & 0.407 & 0.686 \\
$\mathrm{R}^{2}$ & 0.009 & & \\
$\mathrm{~F}$ & 0.217 & & \\
Sig. & 0,806 & & \\
$\quad$ & & \\
$\quad$ The main effect & & & \\
Age Company & 0.230 & 0.230 & 0.819 \\
Company Size & 0.084 & 0.605 & 0.548 \\
Organizational resilience & 0.310 & 2.279 & \\
$\mathrm{R}^{2}$ & 0.104 & & \\
$\mathrm{~F}$ & 1.889 & & \\
$\Delta \mathrm{R}^{2}$ & 0.095 & & \\
$\Delta \mathrm{F}$ & 1.672 & & \\
Sig. & 0.144 & & \\
\hline
\end{tabular}


control variable does not meet the requirements and cannot be used as additional consideration for the researcher.

\section{First hypothesis testing (H1)}

Hypothesis 1 states that organizational resilience has a positive effect on the survival of the company. To test hypothesis 1 , the first step taken is to calculate the average score of the organizational resilience variable and the company's survival of all respondents. The second step is to regress the average score of the organizational resilience variable against the mean score of the firm's survival variable apart from the control variable. Hypothesis 1 says: Organizational resilience has a positive effect on the survival rate of the company.

The simple regression test results show the value of the beta coefficient, the $t$ value, and the significance value of organizational resilience are positive and significant to the company's survival. ( $\beta=$ $0.308 ; \mathrm{t}=2.309$; sig.0.025) (see table 7). From this information it can be concluded that organizational resilience has a positive effect on the survival of the company. When compared with the results of the interaction test of the organizational resilience variable and the control variable (see table 6 ), it can be seen that the control variable actually reduces the influence between the organizational resilience variable and the company's survival. However, in this study, the control variable was not included in the main concern of the study so that it did not affect the conclusion for this hypothesis 1 (one). From the above explanation, it can be concluded that hypothesis 1 is supported.

\section{Second Hypothesis Testing (H2)}

Hypothesis 2 states that: Environmental turmoil moderates the relationship between organizational resilience and company's survival. In conditions of high environmental volatility, the positive influence of the company's organizational resilience on the company survival rate is greater than in conditions of low environmental volatility. The results in Table 8 explain that the organizational

Table 7. Regression Results of Organizational Resilience Against Company's Survival

\begin{tabular}{lllllll}
\hline $\begin{array}{l}\text { Variable } \\
\text { Coefficient }\end{array}$ & Value $\mathbf{t}$ & $\begin{array}{l}\text { Adjusted } \\
\mathbf{R}^{\mathbf{2}}\end{array}$ & $\mathbf{F}$ & Sig. & Description \\
$\begin{array}{l}\text { Organizational } \\
\text { resilience }\end{array}$ & 0.308 & 2.309 & 0.077 & 5.334 & 0.025 & supported \\
\hline
\end{tabular}

$\mathrm{N}=53 ;{ }^{*} \mathrm{p}<0.05$. Source: SPSS data processing results attachment 4 . 
resilience variable in groups with high and low levels of environmental turmoil is positive but not significant for the company's survival variable $(\beta$ low $=0.155 ; t=0.771$; sig. 0.448$)($ $\beta$ high $=0.274 ; t=1.426$; sig. 0.166). The results of the chow test show that $F$ count (calculated $F$ value $=1.207$ ) is smaller than $F$ table ( $F$ table value $=3.19$, significance 0.05 ). Because $F$ count is smaller than $\mathrm{F}$ table, it can be concluded that environmental fluctuation is not able to moderate the positive relationship between organizational resilience and firm survival, although the beta coefficient value of the high environmental fluctuation group is greater than low environmental fluctuation, which means that the effect of organizational resilience is higher in high group compared to low group. From this explanation it can be concluded that the second hypothesis is supported.

This study proposes two research hypotheses, namely one direct effect hypothesis and one moderating hypothesis. In this study, the first hypothesis, namely the direct effect of the organizational resilience variable on the company's survival, is significantly supported, but the moderation of the environmental fluctuation variable in the second hypothesis is not supported.

Hypothesis 1 states that organizational resilience has a positive effect on the company's survival rate. The results of hypothesis testing in Table 4.8 show that the effect of organizational resilience on company's survival is significant so that hypothesis 1 is supported. These results provide empirical support for the research of Hamel and Valikangas (2003); Rose (2004); Carmelli and Markman (2011), Bhamra et al. (2011) and Annarelli and Nonino (2016).

Organizational resilience begins with the main idea, namely strategies that constantly change according to trends, organizations that continually build the future and revolutionary changes that

Table 8. Comparison result of regression in the group of low \& high environmental

\begin{tabular}{llllll}
\hline Group of Turmoil & $\begin{array}{l}\text { Value of } \\
\text { Coefficient (Beta) }\end{array}$ & Value of $t$ & Sig. & $\begin{array}{l}\text { Chow Test } \\
\text { (F count) }\end{array}$ & F table \\
\hline Low & 0.771 & & & 0.155 & 3.19 \\
& 0.448 & & & & \\
High & 1.207 & 1.426 & 0.166 & & \\
\hline
\end{tabular}

$\mathrm{N}=53 ; \mathrm{p}<0.05 *$ table $\mathrm{F}$ with a significance of 0.05 . Source: SPSS data processing results attachment 4 . 
come quickly (Hamel \& Valikangas, 2003). With this organizational resilience capability, the company will be better prepared to face unexpected events in the future (Bhamra et al., 2011). To be able to master it, companies must master four main challenges, namely overcoming resistance, having various values, freeing up resources and embracing extraordinary thinking (Hamel \& Valikangas, 2003). By looking at these characteristics, indirectly the ability of organizational resilience is able to support a company to always adapt and create its own environment so that it is not pushed out and threatened by environmental uncertainty.

Adaptability is part of organizational resilience (Folke et al., 2010), where adaptability represents the capacity to adjust the triggers for change from the external environment to the company's internal processes. Furthermore, companies need to carry out a transformation process in which the company crosses critical boundaries to reach new things by taking advantage of the crisis as a window of opportunity to innovate (Folke et al., 2010).

Management that builds organizational resilience capabilities can sustain the company in the face of shock, uncertainty, and complexity (Folke et al., 2002) and also maintains a variety of elements that are adapted to new circumstances so as to increase the reach that the company can overcome. One of the strategies to obtain high corporate survival is to have an organizational structure that has a high level of organizational resilience (Watanabe et al., 2002). So, organizational resilience does not only have an impact on the smooth running of the company's internal operating system, but is able to increase the company's reach in dealing with problems arising from environmental obscurity.

In view of the main theory in this study, namely the environmental exchange theory, when companies have the ability of organizational resilience that is more forward-looking rather than defensive towards the past (Seeger et al., 2005), the company will be more prepared to create its own environment. In the environmental exchange theory, it is stated that companies depend on the resources owned by other companies in a certain environment, and make organizational resilience ability as an insight into what needs to be prepared so that it does not only depend on existing environmental conditions. By not only depending on the external environment, the company is better able to control its own survival. When collided with the ecological population theory, Journal of Islamic Economics, Management, and Business-Vol 2. No.1 (2020 
companies seem to have no power to face external environmental threats and must always adapt if they want to stay alive.

From the above explanation, it can be added that what determines the life of a company is not only the environment but also how the company manages its resources so that it is more forward-looking and has readiness to overcome uncertainty, because companies that are able to survive are companies that know their own strengths and weaknesses (Valikangas \& Merlin, 2005). The environmental exchange theory makes company resources a tool for controlling the external environment so that the company's life can be more preserved. A balanced relationship between one company and another makes them protect each other's resources (Emerson, 1962) which makes it that no one company is more powerful to kill another company.

The concept of organizational resilience in this case is only a tool to gain legitimacy from the external environment by looking at the opportunities and weaknesses of the company by building a strong supply chain with related companies (Petit et al., 2013). Petit et al (2003) also added that management practices that rely on stable conditions will be challenged by external pressures and volatile changes. Managing risks in an uncertain future is a challenge in itself that requires a high resilience ability to survive, adapt and grow in the face of volatile changes.

These findings provide additional insights into organizational resilience, which in the Indonesian context organizational resilience is also able to boost the level of life of companies, especially SMEs. In line with research conducted by Bhamra et al. (2013), SMEs are an entity that is very vulnerable to disruption from the external environment that is able to paralyze the business journey of SMEs, Special abilities are needed to be able to prevent and face challenges at any time and organizational resilience is very close to the process of prevention and the ability to deal with disturbances the unexpected every time.

In Indonesia it is the same as developing countries in general, namely the majority economy is supported by SMEs. So far, the growth of SMEs in Indonesia is still positive, according to BPS data for the last five years, the contribution of SMEs to GDP has increased from 57.84 percent to 60.34 percent. Employment has also increased, from 96.99 percent to 97.22 percent. This shows that 
the level of organizational resilience that affects the level of life of the company is also increasing.

Even though this study found a weak relationship, this positive influence can be used as a reference that the company has important organizational resilience capabilities as expressed by Hamel and Valikangas (2003). The organizational resilience ability must be owned by companies because many companies are out of control. the market and most companies cannot be taken over easily, so this means that companies that have experienced a decline in performance will disappear by themselves if there is no backup plan, namely takeover. Fiksel (2015) also states that organizations need to improve complex supply chains and foster resilience capabilities by understanding their weaknesses so that future needs will be better maintained and the risk of bankruptcy decreases.

Hypothesis 2 in this study is that environmental volatility moderates the relationship between organizational resilience and company's survival, where in conditions of high environmental turmoil, the positive effect of the company's resilience ability on the company's survival rate is greater than in conditions of low environmental turmoil. The results of hypothesis testing in Table 8 show that the hypothesis is not supported, that is environmental fluctuation is not able to moderate the relationship between organizational resilience and company's survival because $F$ count is smaller than $\mathrm{F}$ table.

This result is not in line with the research conducted by Seeger et al. (2005); Akgün and Keskin (2014) and Gunasekaran et al. (2011), where previous research states that companies are able to anticipate risks originating from the external environment, driven by organizational resilience when the company is a high level of competition and environmental turmoil. The higher the environmental fluctuation around the company, the higher the company's resilience will also affect the company's survival rate.

Although many of the previous researchers supported this second hypothesis, there are interesting things that were obtained from the results of this study which showed that it was not in line with some of the previous researchers. In this study the beta $(\beta)$ value of the research results showed changes and supported the second hypothesis, but the value significance does not meet the 
tolerance target of $5 \%$ or $10 \%$ required in this study so that the results cannot be said to have an empirical effect. This is possible because of the shortcomings in the research, namely the majority of the research samples studied were companies that had only been operating between three to five years as many as $62.26 \%$. This result could be because companies in the young age range have not been able to experience significant technological changes.

This statement is supported by research conducted by Nunes and Serrasqueiro (2012), that there are differences in the determinants of survival rates in younger firms and older companies. The survival rate of young companies is more influenced by the scale of the company, the financial situation and the macroeconomic situation. Meanwhile, companies with old age (in his research explained that companies aged more than 10 years) are more influenced by the intensity of technological development. In this study, the majority of the sample was still at a young age, namely between three and five years as many as $62.26 \%$ and the moderating factor used in this study was environmental fluctuation, one of which was seen from the side of technological change.

In line with the statement issued by the Indonesian Internet Service Providers Association (APJII), the beginning of massive technological developments in Indonesia was 2012, in which this year the development of e-commerce and the development of technology was very rapid, with almost $95 \%$ of internet users opening social media in their daily life (Respati, 2014). The preferences obtained from social media make an increase in variations in customer demand, in this case which will cause shocks for the old company to always update brand products.

One concept that can explain the unsupportedness of hypothesis 2 in this study is stated by Teixeira and Werther (2013) who explain that the concept of organizational resilience is longterm by continuously updating its competitive advantage. They stated that the factors that need to be considered in the concept of organizational resilience do not only come from the external company but also the internal company, namely competitive advantage.

The data in this study explain that external factors are considered only to be able to slightly influence company performance in increasing the company's survival. This proves that the internal factors of the company originating from individuals in 
the organization have a greater role in increasing the influence of organizational resilience (Lengnick-Hall et al., 2011). By increasing the ability of individuals in the internal company, it will indirectly increase the ability of the organization to prepare for and face the possibility of uncertainty in the external environment of the company.

According to Jones et al. (2014) one of the factors that is quite important in dealing with the ambiguity caused by the environment is by strengthening supply chains and relationships with related organizations. By increasing internal relations, the company will be able to be stronger than within the organization itself so that it is more independent in dealing with problems that arise suddenly. Likewise, by increasing good relations with suppliers and distributors, external obscurity will also be reduced.

In addition to external factors that come from the environment, internal company factors also need to be considered in seeing how the relationship between company organizational resilience affects the company's survival rate. It is in line with what Hamel and Valikangas (2003) stated that in an increasingly turbulent era, the only reliable advantage is a superior capacity to rediscover the business model of the company before circumstances force the company to find it.

According to the explanation of Pfeffer (1978) which states that interdependence between companies will always exist and one actor cannot control the overall outcome of the relationship. In general, actors can only control the process for the achievement of results, not the results themselves. If it is related to the results of this study, the company is only able to maximize the resources it has to survive while controlling the results of its own resources.

\section{Conclusion}

From the research data, the results show that organizational resilience has a positive effect on the company's survival. Therefore, this study supports many previous studies that the ability of organizational resilience is very important for companies to avoid threats that can cause the company's operating processes to stop. Although the ability of company resilience is not the only ability that 
must be possessed, the ability of organizational resilience can be used as an addition so that the company is able to continue to exist.

Although according to previous research, it is stated that environmental fluctuation is one of the moderating factors for the JIEMB | 26 company's resilience capability. In this study, environmental fluctuation is not significant in moderating the effect of organizational resilience ability and company survival. This could be due to the fact that the average age of the company is still low so that it has not experienced significant environmental changes.

Practitioners are advised not to have only one specific ability to improve the survival of the company, it takes a complex and strong set of systems so that when shocks or threats occur, the company is not easily shaken.

In this study there are limitations and shortcomings, including a measuring tool for the ability of organizational resilience which is still new and at the previous research development stage it is a challenge for researchers to obtain adequate measuring instrument reliability. In addition, a larger and more varied sample size will provide better research results, namely by increasing the number and category of industry, as well as the level of business not only for SMEs but also for larger companies.

\section{References}

Akgün, A. E., \& Keskin, H. (2014). Organisational resilience capacity and firm product innovativeness and performance. International Journal of Production Research, 52(23), 6918-6937.

Akgün, Ali.E., \& Keskin, Halit. (2014). "Organisational Resilience Capacity and Product Innovativeness and Performances." International Journal of Production Research, 52, (23). 6918-6937.

Annarelli, A., \& Nonino, F. (2016). "Strategic And Operational Management of Organisational Resilience: Current State of Research and Future Directions." Omega 62, (1). 1-18.

Ates, A., \& Bititci, U. (2011). Change process: a key enabler for building resilient SMEs. International Journal of Production Research, 49(18), 5601-5618.

Bhamra, R., Dani, S., \& Burnard, K. (2011). Resilience: the concept, a literature review and future directions. International journal of production research, 49(18), 5375-5393. 
Blau, P. M. (1964). Social exchange theory. Retrieved September, 3(2007), 62.

Carmeli, A., \& Markman, G. D. (2011). Capture, governance, and resilience: Strategy implications from the history of Rome. Strategic Management Journal, 32(3), 322-341.

Carpenter, M. A., Marta A. Geletkanycz, dan Wm. Gerard Sanders. 2004. "Upper Echelons Research Revisited: Antecedents, Elements, and Consequences of Top Management Team Composition." Journal of Management 30, no. 6: 749-778.

Carpenter, S., Walker, B., Anderies, J. M., \& Abel, N. (2001). From metaphor to measurement: resilience of what to what?. Ecosystems, 4(8), 765-781.

Chi, T., \& Sun, Y. (2013). Development of firm export market oriented behavior: Evidence from an emerging economy. International Business Review, 22(1), 339-350.

Cooper, D. R., \& Schindler, P. S. (2011). Qualitative research. Business research methods, 4(1), 160-182.

Covin, J. G., \& Slevin, D. P. (1989). Strategic management of small firms in hostile and benign environments. Strategic management journal, $10(1), 75-87$.

Dalziell, E. P., \& McManus, S. T. (2004). Resilience, vulnerability, and adaptive capacity: implications for system performance.

Dawson, J. F., \& Richter, A. W. (2006). Probing three-way interactions in moderated multiple regression: development and application of a slope difference test. Journal of applied psychology, 91(4), 917.

Emerson, R. M. (1962). Power-dependence relations. American sociological review, 31-41.

Fiksel, J. (2015). Resiliby Design: Creating Businesses That Adapt and Flourish in a Changing World. Island Press.

Folke, C., Carpenter, S. R., Walker, B., Scheffer, M., Chapin, T., \& Rockström, J. (2010). Resilience thinking: integrating resilience, adaptability and transformability. Ecology and society, 15(4).

Gibson, C. A., \& Tarrant, M. (2010). A'conceptual models' approach to organisational resilience. Australian Journal of Emergency Management, The, 25(2), 6-12.

Gunasekaran, A., Rai, B. K., \& Griffin, M. (2011). Resilience and competitiveness of small and medium size enterprises: an empirical research. International journal of production research, 49(18), 54895509.

Hamel, G., \& Valikangas, L. (2003). En busca de la resiliencia. 
Hardesty, D. M., \& Bearden, W. O. (2004). The use of expert judges in scale development: Implications for improving face validity of measures of unobservable constructs. Journal of Business Research, 57(2), 98-107.

Holling, C. S. (1973). Resilience and stability of ecological systems. Annual review of ecology and systematics, 4(1), 1-23.

Jaworski, B. J., \& Kohli, A. K. (1993). Market orientation: antecedents and consequences. Journal of marketing, 57(3), 53-70.

Jemison, D. B. (1981). Organizational versus environmental sources of influence in strategic decision making. Strategic Management Journal, 2(1), 77-89.

Lengnick-Hall, C. A., Beck, T. E., \& Lengnick-Hall, M. L. (2011). Developing a capacity for organizational resilience through strategic human resource management. Human resource management review, 21(3), 243-255.

Miller, D., \& Toulouse, J. M. (1986). Chief executive personality and corporate strategy and structure in small firms. Management science, 32(11), 1389-1409.

Naidoo, R., \& Leonard, A. (2007). Perceived usefulness, service quality and loyalty incentives: Effects on electronic service continuance. South African Journal of Business Management, 38(3), 39-48.

Naidoo, V. (2010). Firm survival through a crisis: The influence of market orientation, marketing innovation and business strategy. Industrial marketing management, 39(8), 1311-1320.

Newbert, S. L. (2008). Value, rareness, competitive advantage, and performance: a conceptual-level empirical investigation of the resource-based view of the firm. Strategic management journal, 29(7), 745-768.

Petit, F. D. P., Bassett, G. W., Black, R., Buehring, W. A., Collins, M. J., Dickinson, D. C., ... \& Peerenboom, J. P. (2013). Resilience measurement index: An indicator of critical infrastructure resilience (No. ANL/DIS-13-01). Argonne National Lab.(ANL), Argonne, IL (United States).

Pfeffer, J., \& Salancik, G. R. (2003). The external control of organizations: A resource dependence perspective. Stanford University Press.

Pratono, A., \& Mahmood, R. (2014, June). Moderating Impact of Environmental Turbulence in the Relationship between Entrepreneurial Management and Firm Performance. In Pratono, $\mathrm{AH}$, \& Mahmood (2014)." Moderating Impact of Environmental Turbulence in the Relationship between Entrepreneurial Management and Firm Performance" Presented for The 3rd International Conference on Social Science and Business. 
Subanar Harimurti, 2001. Manajemen Usaha Kecil , (Yogyakarta: Fakultas Ekonomi UGM).

Visita, L. (2016). Pengaruh jarak psikis pada internasionalisasi interregional dengan orientasi kewirausahaan sebagai pemoderasi: studi pada usaha kecil menengah Indonesia. Thesis work. Yogyakarta: Universitas Gadjah Mada.

Wang, M. C., \& Fang, S. C. (2012). The moderating effect of environmental uncertainty on the relationship between network structures and the innovative performance of a new venture. Journal of Business \& Industrial Marketing. 
Ahmad Saiful Affa, Muh. Ghafur Wibowo, Izra Berakon

JIEMB | 30

Journal of Islamic Economics, Management, and Business-Vol 2. No.1 (2020 